\title{
Development and properties of advanced composites based on cork and nanometric silicon carbide-filled phenolic resin
}

\author{
G PELIN $1,2, * @$, C-E PELIN ${ }^{1}$, A ŞTEFAN ${ }^{1}$, I DINCÁ $^{1}$, E ANDRONESCU $^{2}$, O OPREA $^{2}$, D FICAI $^{2}$ \\ and R TRUŞCĂ ${ }^{2}$ \\ ${ }^{1}$ Materials Unit, National Institute for Aerospace Research 'Elie Carafoli', 061126 Bucharest, Romania \\ ${ }^{2}$ Faculty of Applied Chemistry and Materials Science, Politehnica University of Bucharest, \\ 011061 Bucharest, Romania \\ *Author for correspondence (pelin.george@incas.ro, george.pelin@yahoo.com)
}

MS received 8 July 2016; accepted 26 October 2017; published online 5 February 2018

\begin{abstract}
This paper presents the obtaining of advanced materials based on cork powder as reinforcement and phenolic resin $(\mathrm{PR})$ with silicon carbide $(\mathrm{nSiC})$ nanofiller as matrix with potential applications in aerospace industry. Three formulations were obtained: one control sample PR/cork with no nanofiller, two nanofilled samples with 1 and $2 \mathrm{wt} \% \mathrm{nSiC}$ loadings into the resin. The materials were tested by flexural and compressive mechanical tests to determine their strength and stiffness, to determine their friction coefficient by tribological tests, to determine their thermal decomposition behaviour by TG-DSC analysis and to evaluate their thermal behaviour by thermal shock tests when subjected to extreme temperature directly from room temperature. The material structure was analysed by SEM visualizing the fracture cross-section after mechanical testing. The test results illustrate that silicon carbide nanoparticles improve flexural and compressive strength, but also stiffness and friction coefficient, delay thermal decomposition onset and improve thermal shock resistance. All these sustain the $\mathrm{PR} / \mathrm{nSiC} /$ cork materials as potential advanced materials candidates for thermal protection applications.
\end{abstract}

Keywords. Cork phenolic; silicon carbide nanoparticles; thermal shock resistance; mechanical strength.

\section{Introduction}

Thermal protection systems (TPS) are key elements for prevention of excessive heat reaching the metallic structure in spacecraft missions. There are two basic concepts of thermal protection systems: reusable materials, i.e., carbon-carbon composites and non-reusable, i.e., ablative materials (ablators). The selection of one of the two categories is done based on the spacecraft mission and financial restrictions [1].

Reusable systems, such as reinforced carbon-carbon materials are generally used as low-weight tiles in wing-leading edges of space capsules, where temperature can exceed $1260^{\circ} \mathrm{C}$ [2]. For temperatures lower than $1200^{\circ} \mathrm{C}$, materials that are able to withstand several extreme thermal cycles are generally used, these include alumina- or silica-based materials, $\mathrm{C} / \mathrm{SiC}$ and $\mathrm{Cf} / \mathrm{SiC}$ composites [2].

Ablative materials are generally designed for non-reusable planetary probes, as they insulate a large heat amount through phase change, by resin decomposition process that generates the absorption of a large part of this heat, and prevents it from passing to the next layer material [3]. The char layer formed after the resin degradation, acts as an insulator, while the material continues to decompose and outgas $[4,5]$. The nature of the process is endothermic and the pyrolysis gases are heated as they penetrate towards the surface, transferring energy from solid to gas phase [6].

Cork is one of the materials used for numerous space applications due to its intrinsic properties, such as thermal resistance during reentry phase of space vehicles. NorcoatLiege is an ablative material consisting of composites based on phenolic resin (PR) matrix with homogenized cork particles [7], developed by European Aeronautic Defence and Space and used in the rear cone and back-cover section of the atmospheric reentry demonstrator (ARD), a sub-orbital reentry vehicle launched in 1998 by European Space Agency (ESA), that will also intend to use it in ExoMars mission after some adaptation to meet the requirements specific for Mars entry missions [8-10]. Besides ESA's missions, cork was used as insulator between the metal/Kevlar case and the propellant in solid rocket boosters [11], and it is studied for other applications, such as high-performance aircraft structural composites. In this case, cork-filled epoxy composites [12] and cork-filled carbon fibre-reinforced polymer (CFRP) laminates [13] with improved mechanical and impact resistances were obtained. Cork was added to jute/epoxy composites to enhance thermal stability [14], and to EPDM rubber ablative composites to enhance thermal endurance and ablation characteristics [15]. Recent studies present the use of cork as a compound in nanocomposites, aerogel/cork/silicone 
nanocomposites were obtained by Raeisi et al [16], and their results showed that cork pores were filled with aerogel nanostructures and generated density increase and thermal conductivity decrease. However, there are very few studies presenting cork phenolic composites modified with the aid of nanofillers. Inorganic nanofillers such as nanometric silicon carbide ( $\mathrm{nSiC})$, nano-silica, nanoclays, $\mathrm{ZrB}_{2}$ or $\mathrm{BN}$ are promising filler reinforcement agents used to improve processability, toughness, char yield as well as tribological and thermal properties of PR matrix [17,18]. Amongst all nanofillers, silicon carbide presents exceptional properties for high-temperature applications of composites, i.e., oxidative and thermal shock resistance and excellent friction properties [19], as shown in studies presented in literature [20-22]. One previous study conducted by the authors [23] showed significant positive effect that nanometric $\mathrm{SiC}$ had on mechanical, thermo-mechanical and tribological properties of PR as stand-alone material. As a continuation of this research, the current study focussed on using the nSiC-filled PR composites as matrix of cork-based ablative-type materials. The current study presents the obtaining of ablative composites based on cork and PR-filled with silicon carbide nanoparticles in different weight contents, the aim of the paper is the evaluation of the silicon carbide nanoparticles loading effect. The mechanical, tribological and thermal properties show enhanced performance when silicon carbide nanoparticles are present in the ternary composite, sustaining these nanofilled materials as potential candidates for ablators with enhanced properties for advanced applications.

\section{Experimental}

\subsection{Materials}

The resin used as matrix was resole PR ISOPHEN 215 SM $57 \%$ provided by ISOVOLTA S.A. Bucharest, with $1.135 \mathrm{~g} \mathrm{~cm}^{-3}$ density. The material used as preform to be impregnated with resin was cork powder with grain size between 0.5 and $1 \mathrm{~mm}$. $\beta$-type $\mathrm{nSiC}$ powder $(97.5 \%$ purity, $34-40 \mathrm{~m}^{2} \mathrm{~g}^{-1}$ specific surface area and $3.22 \mathrm{~g} \mathrm{~cm}^{-3}$ true density) purchased from Nanostructured \& Amorphous Materials Inc., USA, was used as nanofiller agent.

\subsection{Obtaining procedure}

The PR/nSiC/cork composites were obtained by following a multiple step procedure. For the nanofilled samples, $\mathrm{nSiC}$ was added to the liquid PR in 2 weight contents relative to the resin ( 1 and $2 \mathrm{wt} \%$ ), the mixture was homogenized by mechanical method for 3-5 min and by ultrasonication method (using an ultrasonic probe) for $15 \mathrm{~min}$ in steps of $5 \mathrm{~min}$. Cork powder was added to the obtained mixture at a weight ratio of 1:5 (cork:resin), that was further mechanically homogenized. The ternary mixtures were placed in an air oven at $65-70^{\circ} \mathrm{C}$ for $30 \mathrm{~min}$ to eliminate methanol solvent from the resin

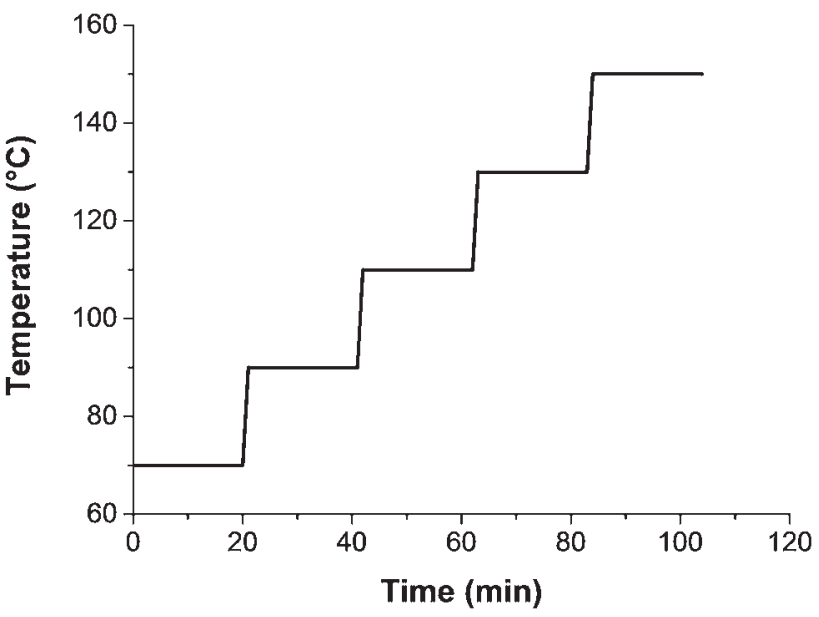

Figure 1. Temperature treatment programme for curing process of the $\mathrm{PR} / \mathrm{nSiC} /$ cork composites.

composition and decrease bubble formation in the bulk composites. The mixture was placed in a mould (covered with a release agent) and the curing process was carried out according to a programme in which temperature was increased in stages, as described in figure 1 . The mould was placed in a hydraulic press at $70^{\circ} \mathrm{C}$ and the temperature was increased by $20^{\circ} \mathrm{C}$ with dwell time of $20 \mathrm{~min}$ at each temperature step. In the $90^{\circ} \mathrm{C}$ step, the pressing of the composites started, using the pressure value of $3 \mathrm{~kg} \mathrm{~cm}^{-2}$. Cooling took place under pressure down to room temperature.

\subsection{Testing and characterization}

The materials were tested by mechanical, tribological and thermal tests. Prior to the nanocomposite obtaining process, the liquid PR and nanofilled PR were subjected to viscosity measurements using Ubbelohde capillary tube viscometer (Cannon CT-1000). Mechanical testing was performed at room temperature using INSTRON 5982 mechanical testing machine and consisted of 3-point bending and compression tests. 3-point bending tests were performed according to SR EN ISO 178 [24], at $2 \mathrm{~mm} \mathrm{~min}^{-1}$ testing speed and using nominal span length $(16 \times$ specimen thickness) on rectangular specimens $(80 \times 15 \times 4 \mathrm{~mm})$ using five specimens per sample. Compressive properties were measured according to ASTMD 1074 [25] at $1.3 \mathrm{~mm} \mathrm{~min}^{-1}$ testing speed on cylindrical specimens with $12.7 \mathrm{~mm}$ diameter and $4 \mathrm{~mm}$ height using five specimens per sample. After mechanical testing, the fracture cross-section was analysed by scanning electron microscopy (SEM) using FEI Inspect F50 high-resolution SEM with field emission gun and $1.2 \mathrm{~nm}$ resolution and energy dispersive $\mathrm{X}$-ray spectrometer (EDS). Tribological tests were performed on CETR UMT 3 (Universal Macro Materials Tester) blockon ring module, using $35 \mathrm{~mm}$ diameter steel role, under $10 \mathrm{~N}$ load, for $60 \mathrm{~s}$ at 1000 and $1500 \mathrm{rpm}$, testing three specimens for each sample. Thermal degradation behaviour was followed by TG-DSC (Netzsch TG 449C STA Jupiter), 


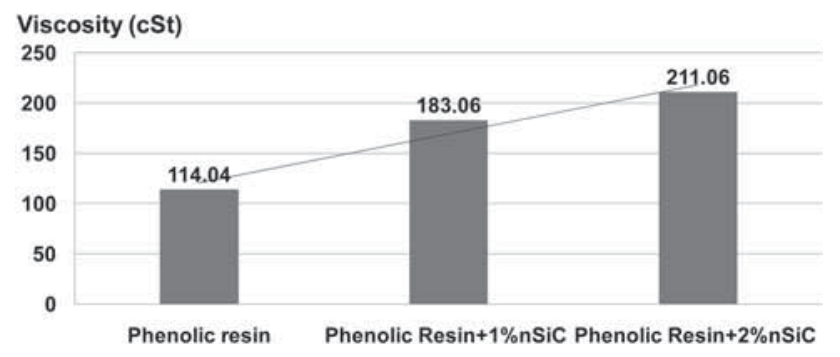

Figure 2. Viscosity increase as a function of $\mathrm{nSiC}$ content into the liquid PR.

heating with $10 \mathrm{~K} \mathrm{~min}^{-1}$ from 25 to $900^{\circ} \mathrm{C}$ in $50 \mathrm{ml} \mathrm{min}^{-1}$ Ar flow and from 900 to $1000^{\circ} \mathrm{C}$ in $50 \mathrm{ml} \mathrm{min}^{-1}$ dry air flow. Thermal shock tests were performed in air in a Nabertherm carbonization oven introducing the sample from room temperature directly at $1100^{\circ} \mathrm{C}$ and maintaining it for three different time lapses (30,60 and $120 \mathrm{~s}$ ), weight loss was measured as a function of time.

\section{Results and discussion}

\subsection{Nanofilled resin viscosity measurements}

Viscosity measurements were performed at $25^{\circ} \mathrm{C}$ (using the thermostat bath that the viscometer is equipped with) on the liquid $\mathrm{PR}$ with and without $\mathrm{nSiC}$ filler, after ultrasonication of the mixtures. Using the Ubbelohde viscometer, suitable for polymeric solutions [26], minimum three measurements were performed for each sample. The kinematic viscosity was calculated as a ratio between the capillary constant $\mathrm{K}$ (expressed in $\mathrm{mm}^{2} \mathrm{~s}^{-1}$ ) and the mean flow time (expressed in seconds) [27].
The graphic in figure 2 illustrates a linear increase of the mixtures viscosity with $\mathrm{nSiC}$ weight content increase into the PR. The standard deviation values for the viscosity average values are situated between 0.3 and 1.4, suggesting that the results are reproducible and also that the mixtures remained homogenized during the experiment. This property is important for the homogenization of cork powder into the nanofilled resin mixtures to obtain the ablative type composites.

$\mathrm{nSiC}$ presence does not generate excessive viscosity increase and the values remain in the medium range. Too high viscosity of the mixtures would hinder the uniform homogenization of the cork powder into the nanofilled polymeric matrix that would lead to non-uniformity areas in the final composites, while too low viscosity would lead to resin material loss during curing-pressing stage that would generate low matrix contents and air gasps into the composite and poor adhesion between the phases.

\subsection{Mechanical testing}

Mechanical testing consisted of 3-point bending (flexural) and compression tests performed both on control samples and nSiC-filled samples. In the case of flexural testing, the load was applied until reaching conventional deflection (deflection equal to $1.5 \times$ specimen thickness) according to the standard recommendations, but all tested specimens fractured before this value was reached, suggesting the brittle nature of the materials, as the standard indicates.

Figures 3 and 4 present the stress-strain curves obtained during the 3-point bending and compressive testing.

The curves allure and strain values lower than 5\% also suggest the brittle nature of the materials.

Table 1 presents the average values of the flexural and compressive properties obtained after testing, the results illustrate that these properties are influenced by $\mathrm{nSiC}$ nanofiller presence and content in the PR/cork composites.

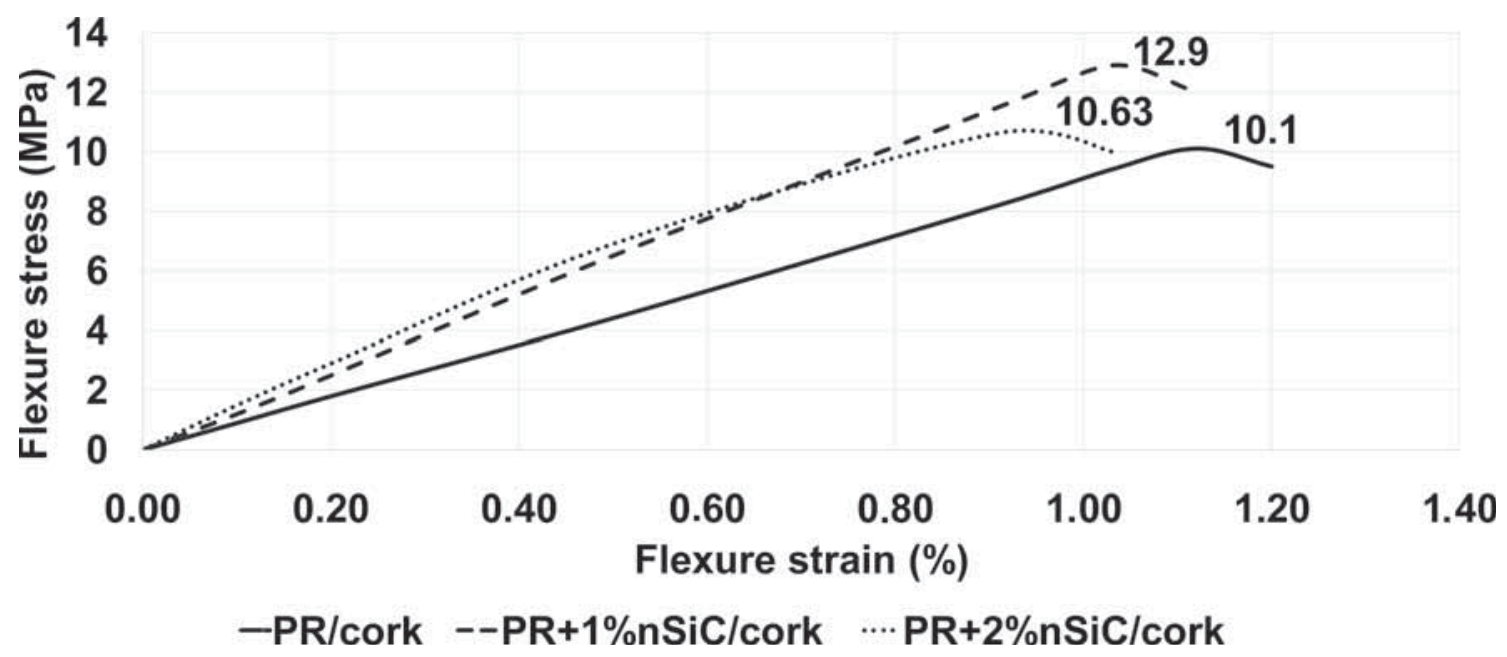

Figure 3. Stress-strain curves during 3-point bending test. 


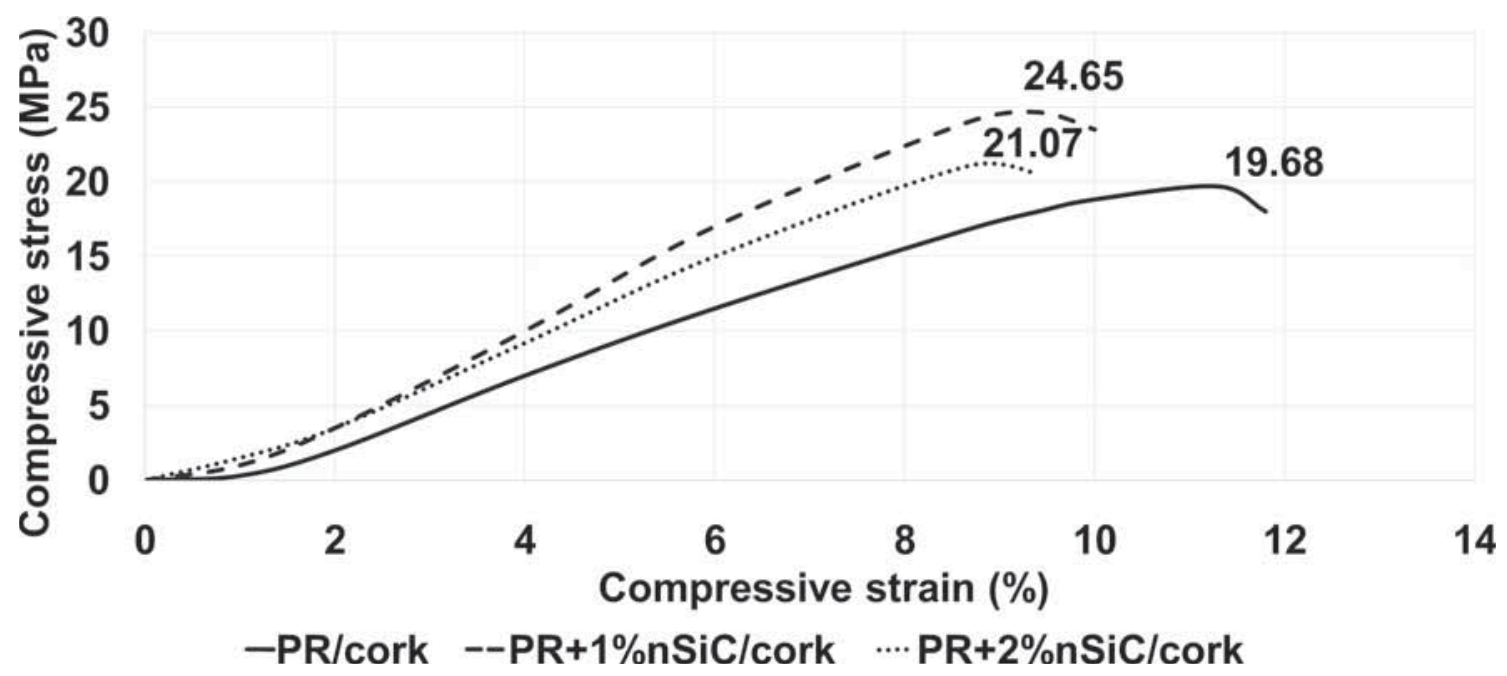

Figure 4. Stress-strain curves during compression test.

Table 1. Mechanical properties of bending and compression of $\mathrm{PR} / \mathrm{nSiC} /$ cork composites.

\begin{tabular}{|c|c|c|c|c|c|}
\hline Sample & $\begin{array}{l}\text { Flexural strength } \\
(\mathrm{MPa})\end{array}$ & $\begin{array}{l}\text { Flexural modulus } \\
(\mathrm{MPa})\end{array}$ & $\begin{array}{l}\text { Strain } \\
(\%)\end{array}$ & $\begin{array}{l}\text { Compressive } \\
\text { strength (MPa) }\end{array}$ & $\begin{array}{l}\text { Compressive } \\
\text { modulus (MPa) }\end{array}$ \\
\hline $\mathrm{PR} /$ cork & $10.1 \pm 0.24$ & $918 \pm 15.3$ & 1.12 & $19.68 \pm 0.69$ & $342.5 \pm 20.9$ \\
\hline $\mathrm{PR}+1 \%$ nSiC/cork & $12.93 \pm 0.15$ & $1145 \pm 18.8$ & 1.03 & $24.65 \pm 0.69$ & $553 \pm 29.3$ \\
\hline $\mathrm{PR}+2 \% \mathrm{nSiC} /$ cork & $10.63 \pm 0.49$ & $1106 \pm 18.9$ & 0.91 & $21.06 \pm 0.62$ & $505.8 \pm 15.5$ \\
\hline
\end{tabular}

$\mathrm{nSiC}$ addition generates strength and modulus increase compared with control sample (PR/cork) both under flexural loading as well as under compressive loading. It can be observed that $1 \% \mathrm{nSiC}$ content generates more significant properties, including increase than higher content of $2 \%$. Compared with the control sample, $\mathrm{PR}+1 \% \mathrm{nSiC} /$ cork shows $28 \%$ higher flexural strength and $25 \%$ higher flexural modulus, while PR+2\% nSiC/cork shows only $5 \%$ higher flexural strength and $20 \%$ higher flexural modulus. The same trend is observed in the case of compressive testing, $1 \% \mathrm{nSiC}$ generates $25 \%$ higher strength and $61 \%$ higher modulus, while $2 \%$ generates 7 and $48 \%$, respectively, higher strength and modulus.

The possible cause for the lower increments of $2 \% \mathrm{nSiC}$ based samples, compared to the ones generated by lower content could be that this higher content generates more agglomeration areas that act as stress concentration sites that influence mechanical behaviour and properties. The positive effect of $1 \% \mathrm{nSiC}$ could be associated with good embedment of the nanoparticles into the resin, generating a homogenous structure of the nanofilled matrix and therefore, of the final composite. This phenomenon was observed also in the case of nanocomposites based on $\mathrm{PR}$ and $\mathrm{nSiC}$ nanofiller studied in the previous work [23]. According to the results presented in the mentioned study, FTIR analysis suggests that the maximum interaction between the resin and $\mathrm{nSiC}$ occurs with the addition of $1 \%$ by weight nanoparticles into the phenolic matrix, the additional content up to $2 \%$ by weight not being able to further interact with the resin. This issue along with the higher viscosity of the $2 \%$-based samples contributes in hindering the uniform dispersion and homogeneity of the materials, therefore, leading to less homogeneous structures.

The structure of the $\mathrm{PR} / \mathrm{nSiC} /$ cork composites was analysed by SEM, further presented.

\subsection{SEM analysis}

SEM analyses were performed in the fracture cross-section of the mechanically tested materials to visualize the interface between the cork phase and the PR matrix, as well as the dispersion of the $\mathrm{nSiC}$ nanoparticles into the phenolic matrix. The SEM images of the three samples registered at different magnification levels are shown in figure 5. PR/cork sample is illustrated in figure $5 \mathrm{a}-\mathrm{c}, \mathrm{PR}+1 \% \mathrm{nSiC} /$ cork in figure $5 \mathrm{~d}-\mathrm{f}$ and $\mathrm{PR}+2 \% \mathrm{nSiC} /$ cork in figure $5 \mathrm{~g}-\mathrm{i}$. At lower magnification levels $(\times 1000)$, in all samples (figure 5a, d, g), it can be observed that the simple or nanofilled resin is distributed on the analysed area, covering at a high extent the cellular structure of the cork. Medium magnification levels of $\times 5000$ illustrate clearly the cells that compose the structure of the cork, and it can be observed that the resin infiltrated into the inner structure of the cork cells. In figure $5 \mathrm{e}$, it can be observed 

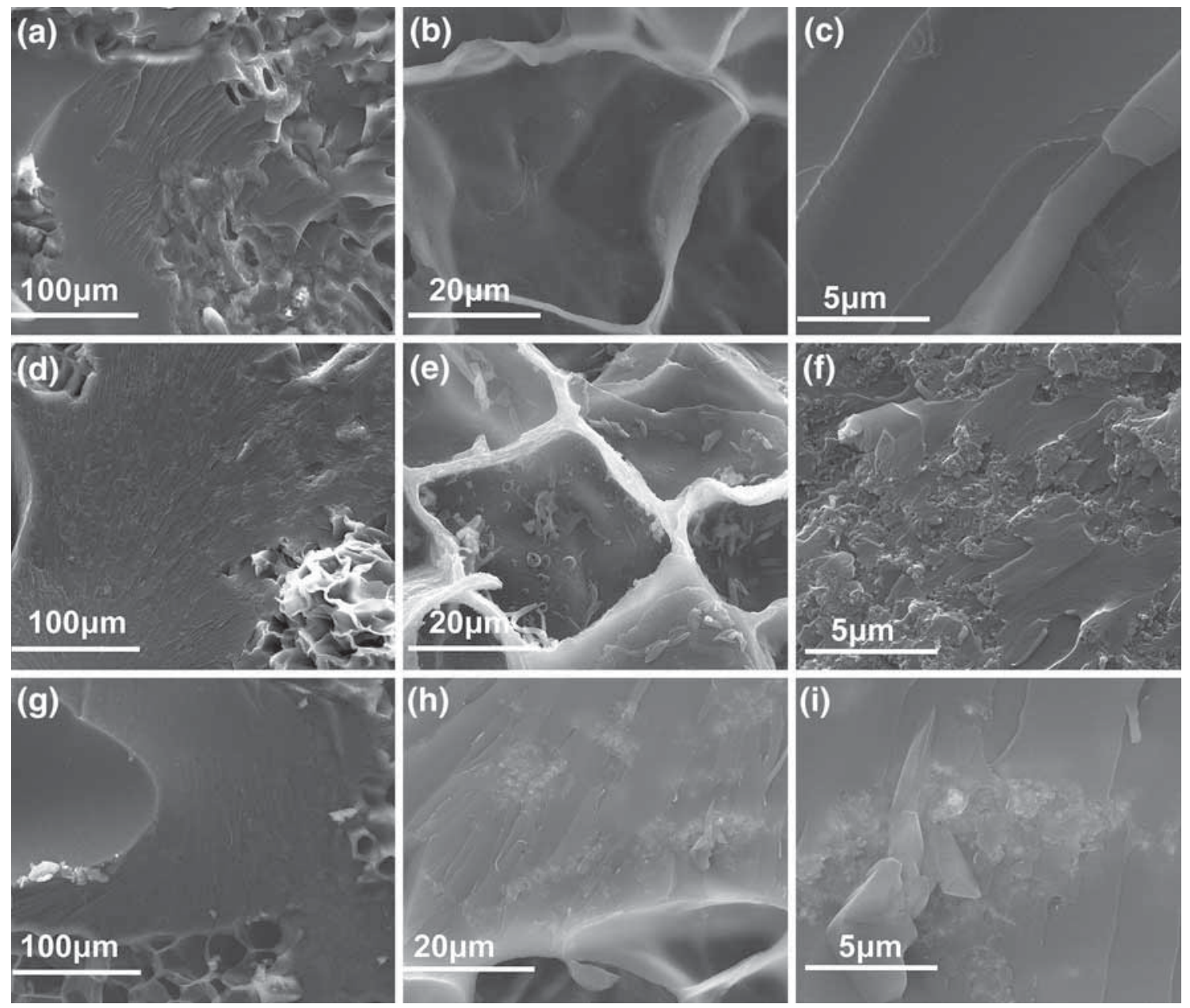

Figure 5. (a) PR/cork at $\times 1000$, (b) $\mathrm{PR} /$ cork at $\times 5000$, (c) $\mathrm{PR} /$ cork at $\times 20000$, (d) $\mathrm{PR}+1 \% \mathrm{nSiC} /$ cork at $\times 1000,($ e) $\mathrm{PR}+1 \% \mathrm{nSiC} /$ cork at $\times 5000,(\mathbf{f}) \mathrm{PR}+1 \% \mathrm{nSiC} /$ cork at $\times 20000,(\mathrm{~g}) \mathrm{PR}+2 \% \mathrm{nSiC} /$ cork at $\times 1000,(\mathbf{h}) \mathrm{PR}+2 \% \mathrm{nSiC} /$ cork at $\times 5000$, (i) $\mathrm{PR}+2 \% \mathrm{nSiC} /$ cork at $\times 20000$.

that the $\mathrm{nSiC}$ nanoparticles embedded into the resin layer are present inside the cellular structure, while figure $5 \mathrm{f}$ shows that the $\mathrm{nSiC}$ nanoparticles are also uniformly dispersed in the matrix on the entire visualized area. It can be noticed that while $\mathrm{PR}+1 \% \mathrm{nSiC} /$ cork sample illustrates visible differences in terms of morphology compared with the unfilled sample, $\mathrm{PR}+2 \% \mathrm{nSiC} /$ cork has a mixed nature morphology. This aspect is highlighted by figure $5 \mathrm{i}$ that shows both areas with high nanoparticles content as well as areas that present the morphology of a simple polymer layer, similar to the one visualized in the control sample in figure $5 \mathrm{c}$.

In the case of $1 \%$ nanofiller sample, the uniform dispersion of $\mathrm{nSiC}$ into the PR is confirmed by EDS analysis (figure 6) that illustrates a perfect distribution of $\mathrm{Si}$ and $\mathrm{C}$ elements on the area, results prove that $\mathrm{Si}$ is present in $41 \%$, while $\mathrm{C}$ in $23 \%$.

Correlating SEM analyses of the fracture cross-section with the mechanical performance of the composites, it can be noticed that in the sample with the highest mechanical performance ( $\mathrm{PR}+1 \% \mathrm{nSiC} /$ cork) SEM analysis confirmed the uniform dispersion of $\mathrm{nSiC}$ nanoparticles in the phenolic matrix of the sample, while in the case of the sample with higher $\mathrm{nSiC}$ content $(\mathrm{PR}+2 \% \mathrm{nSiC} /$ cork) that exhibited a decrease in mechanical performance (compared with $\mathrm{PR}+1 \%$ $\mathrm{nSiC} /$ cork) SEM images showed clear nanoparticles agglomeration areas.

Uniformly dispersed nanoparticles into the matrix of the $\mathrm{PR}+1 \% \mathrm{nSiC} /$ cork composite are able to strength the matrix, allowing better load transfer within the composite system and leading to higher mechanical performance.

\subsection{Tribological testing}

As expected, the addition of abrasive $\mathrm{nSiC}$ nanofiller generates significant increase of friction coefficient, using both speed rate values. Considering the $\mathrm{nSiC}$ mentioned tribological nature, friction coefficient increases with $\mathrm{nSiC}$ content in the composite. At $1000 \mathrm{rpm}$, compared with the PR/cork sample with no nanometric agent, friction coefficient of the 

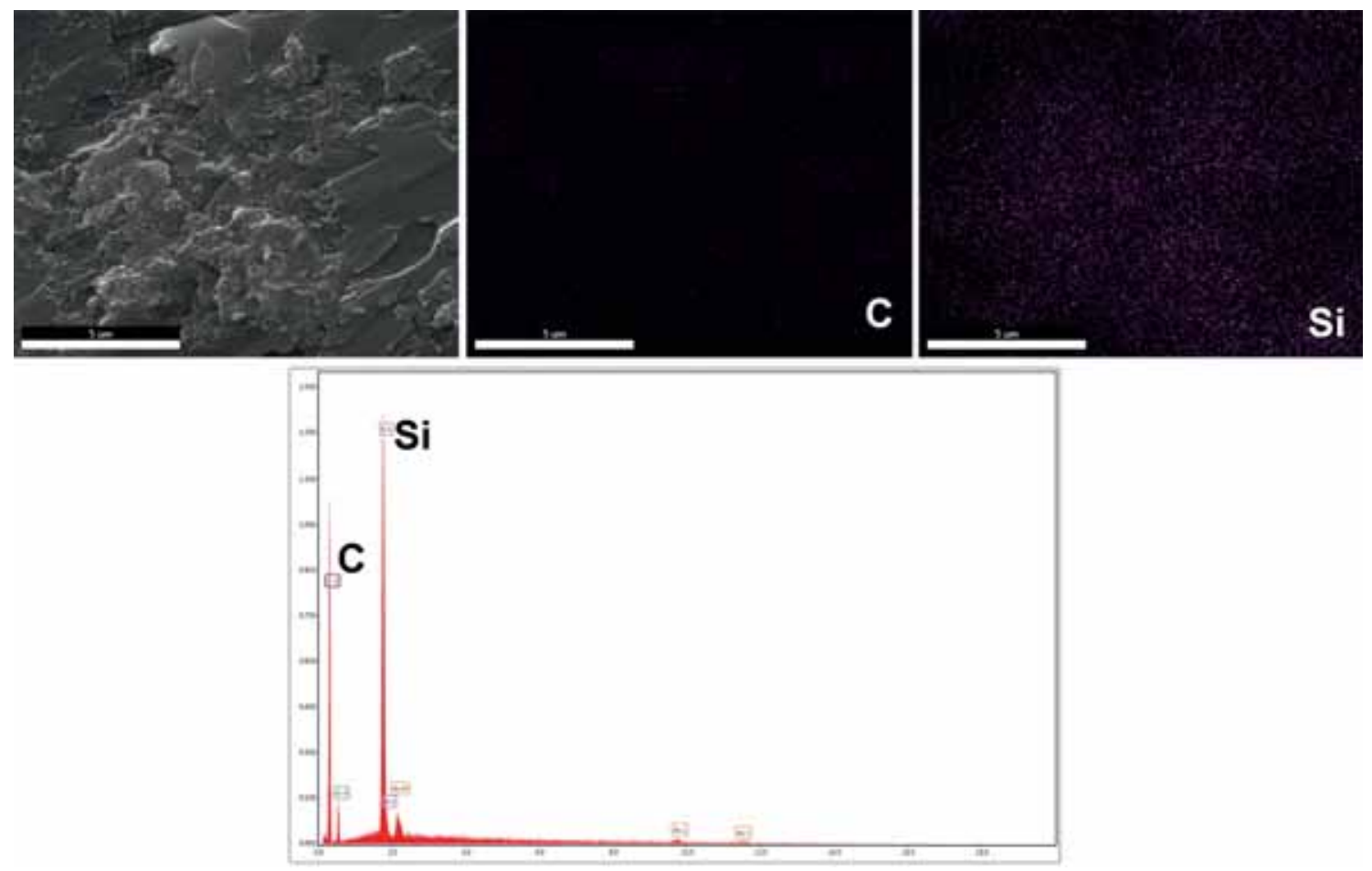

Figure 6. (a) EDS analysis of $\mathrm{PR}+1 \% \mathrm{nSiC} /$ cork cross-section and elemental distribution map of $\mathrm{C}$ and $\mathrm{Si}$; and (b) EDS spectra of the analysed area.

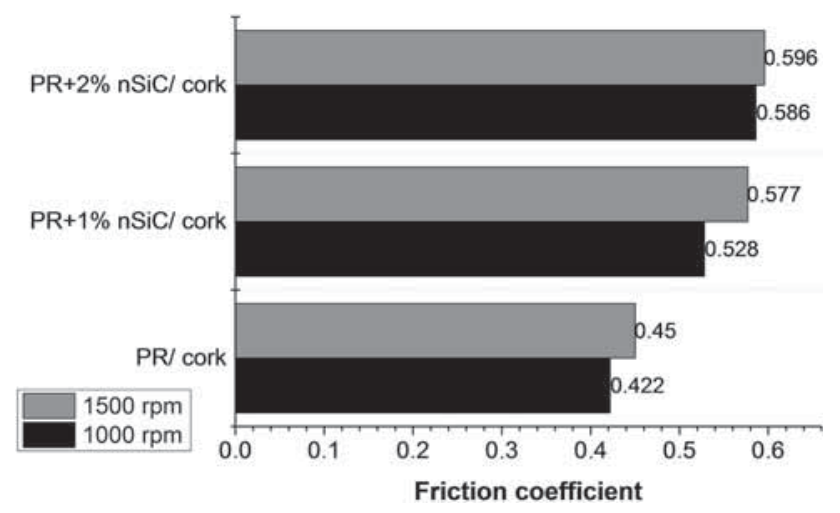

Figure 7. Friction coefficient average values of $\mathrm{PR} / \mathrm{nSiC} /$ cork tested at 1000 and $1500 \mathrm{rpm}$.

nanofilled materials increased by 25 and 39\%, respectively, for 1 - and $2 \%$-based samples. At $1500 \mathrm{rpm}$, the increments were by 28 and $33 \%$ for $1 \%$ and $2 \% \mathrm{nSiC}$ contents into the matrix compared to the control sample (figure 7).

The results presented in the previous work of the authors [23] that studied $\mathrm{PR} / \mathrm{nSiC}$ matrix as self-standing materials showed the same overall trend in friction coefficient variation when adding $\mathrm{nSiC}$ nanoparticles, the abrasive nature of this nanofiller generating higher values of the friction coefficient compared to the unfilled resin. Comparing the tribological properties of the $\mathrm{PR} / \mathrm{nSiC}$ matrix with the properties of the $\mathrm{PR} / \mathrm{nSiC} /$ cork materials, it is worth mentioning that besides the friction coefficient increase generated by the $\mathrm{nSiC}$ nanoparticles, cork agent imprints even higher friction coefficient increments, due to its well-known tribological nature. The obtained results show that the materials could be used as high friction materials in abrasive applications, due to the improved tribological properties.

\subsection{TG-DSC analysis}

Thermogravimetry-differential scanning calorimetry (TGDSC) analysis was performed to evaluate the thermal behaviour of the obtained materials during controlled, linear temperature increase. TG analysis was performed in inert atmosphere (Ar) from room temperature to $900^{\circ} \mathrm{C}$ and in air from 900 to $1000^{\circ} \mathrm{C}$, to perform the combustion of the carbonaceous mass resulted in the previous stage.

Figure 8a illustrating $25-900^{\circ} \mathrm{C}$ range shows that the mass loss occurs smoothly between 100 and $300^{\circ} \mathrm{C}$, probably corresponding to organic compounds decomposition and the highest mass loss percentage occurs between 320 and $700^{\circ} \mathrm{C}$. TG curves between 25 and $900^{\circ} \mathrm{C}$ illustrate the fact that $\mathrm{nSiC}$ addition leads to an increase in the initial temperature of the degradation process, and also, the control sample shows a higher mass loss corresponding to the same temperature. TG curves in the $900-1000^{\circ} \mathrm{C}$ range (figure $8 \mathrm{~b}$ ) illustrate that the sample with no nanofiller suffers a sharper 
(a)

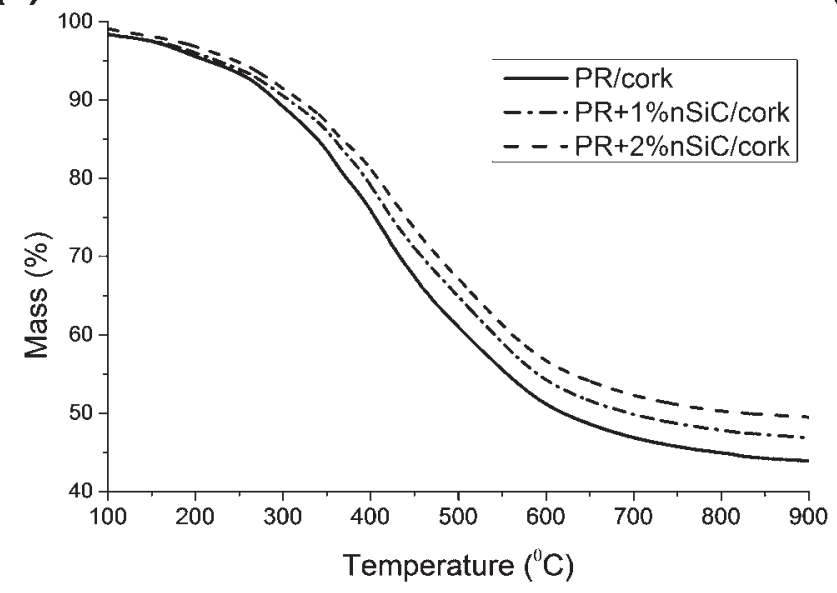

(b)

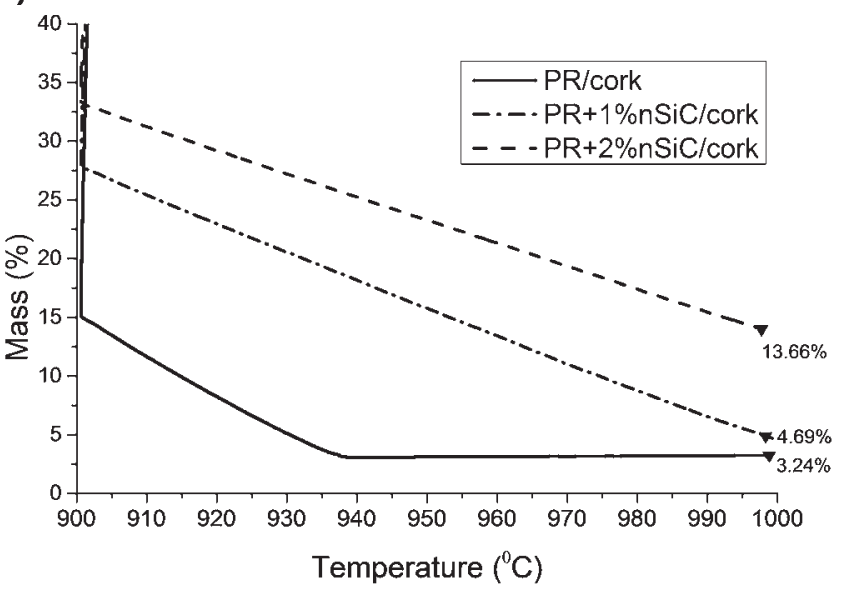

Figure 8. TG curves registered in (a) Ar flow between 25 and $900^{\circ} \mathrm{C}$; and (b) air flow between 900 and $1000^{\circ} \mathrm{C}$.

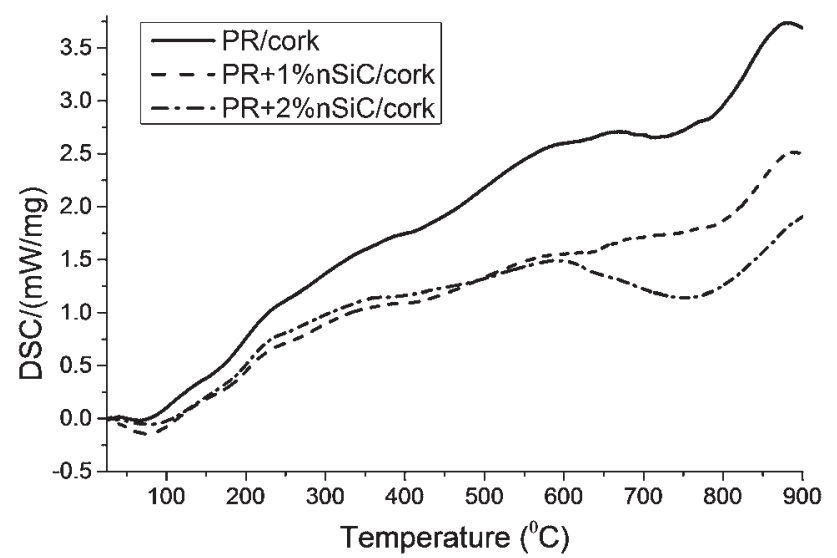

Figure 9. DSC graphs of the cork-based samples tested in inert atmosphere between 25 and $900^{\circ} \mathrm{C}$.

weight loss, $3.24 \%$ residual mass is obtained starting from $940^{\circ} \mathrm{C}$, while nanofilled samples' corresponding curves have a smooth evolution up to $999.4^{\circ} \mathrm{C}$. The residual mass of the $\mathrm{PR}+2 \% \mathrm{nSiC} /$ cork is much higher than that of the control sample and $1 \% \mathrm{nSiC}-$ based sample, which was expected as $\mathrm{nSiC}$ compound with much higher thermal resistance compared to the other phases, is present in higher content. Although the residual mass increases with $\mathrm{nSiC}$ content as expected, but the increase is not proportional. This suggests that the residual mass does not correspond totally to the larger $\mathrm{nSiC}$ quantity, but it contains composite mass, indicating that the thermal stability of the composite is improved.

DSC curves (figure 9) illustrate that thermal degradation of the nanofilled samples starts later than the control sample. Also, the control sample curve slope is higher, suggesting that the exothermic effect is stronger. In the case of the nanofilled samples, the degradation process is delayed and the curves are smoother, due to the $\mathrm{nSiC}$ presence, which acts as a thermal

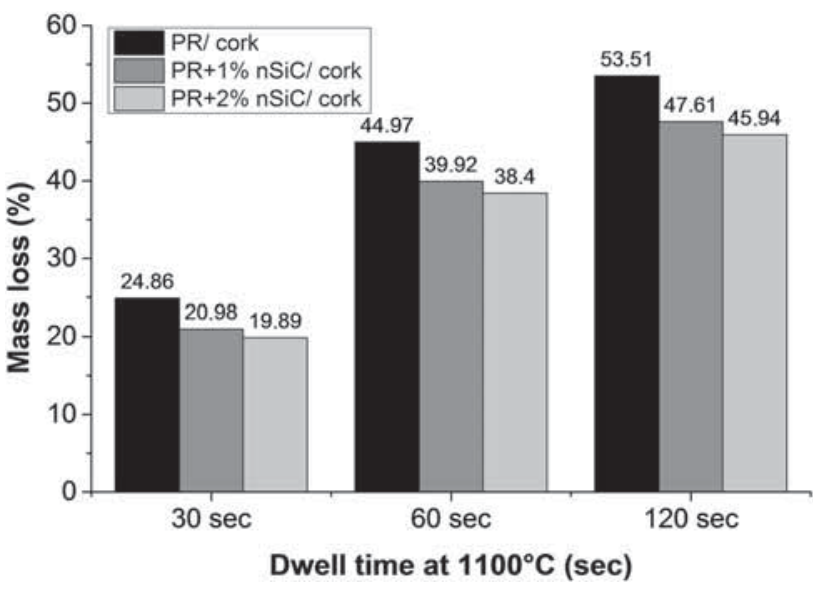

Figure 10. Mass loss percentage of the thermal shock tested samples compared to the virgin samples, after different dwell periods at $1100^{\circ} \mathrm{C}$.

protection agent. In the high temperature region from 600 to $900^{\circ} \mathrm{C}$, one can observe that the $2 \%$ content of $\mathrm{nSiC}$ nanoparticles is able to diminish the effect of thermal degradation.

\subsection{Thermal shock test}

Thermal shock test was performed to evaluate the mass loss function of treatment period at $1100^{\circ} \mathrm{C}$ and test the ablative capacity of the obtained materials. Figure 10 illustrates the mass loss percentage of all the 3 samples (PR/cork, $\mathrm{PR}+1 \% \mathrm{nSiC} /$ cork and $\mathrm{PR}+2 \% \mathrm{nSiC} /$ cork) after the three dwell periods $(30,60$ and $120 \mathrm{~s})$ at $1100^{\circ} \mathrm{C}$, compared with the virgin samples. Two important trends are observed. As expected, by increasing the thermal treatment time, the samples mass decreases, due to the decomposition of the organic compounds (shown by DSC) from the composite chemical structure. Analysing nSiC-based samples, it can be observed 


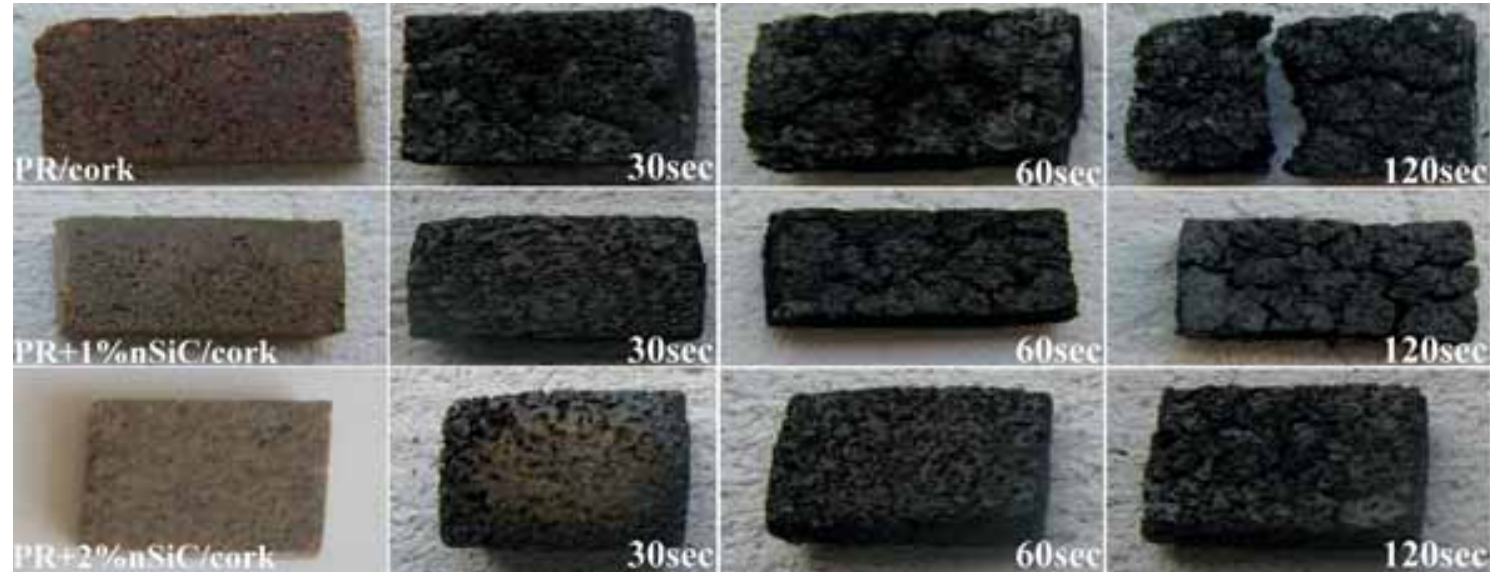

Figure 11. Samples before thermal shock and after $30 \mathrm{~s}$ at $1100^{\circ} \mathrm{C}$, after $60 \mathrm{~s}$ at $1100^{\circ} \mathrm{C}$, after $120 \mathrm{~s}$ at $1100^{\circ} \mathrm{C}$.

that mass loss decreases as nanofiller content increases, due to the excellent thermal resistance [28] of this compound. The $\mathrm{nSiC}$ nanoparticles act as thermal protection agent for the cork-based composite, enhancing its ablative properties. These results are in accordance with TG analysis results concerning residual mass corresponding for each sample.

Figure 11 illustrates the material consumption when thermal treatment time increases. After $120 \mathrm{~s}$ at $1100^{\circ} \mathrm{C}$, the unfilled PR/cork samples suffer rather high extent structure degradation, fracturing into two parts. By analysing the 1 and $2 \% \mathrm{nSiC}$-filled samples appearance, none of them fractured completely, and the sample with higher nanoparticles content shows fewer cracks than the lower content sample. Overall, it can be observed that the nanofilled samples do not suffer extended degradation of the structure, and the materials maintain their integrity, which recommends them as potential candidates for thermal protection (ablative) applications.

\section{Conclusions}

The study presents the obtaining and characterization of corkbased phenolic composites filled with silicon carbide nanoparticles, evaluating the effect generated by the nanofiller. Mechanical, tribological and thermal test results indicate that the addition of $\mathrm{SiC}$ nanoparticles enhances the properties of $\mathrm{PR} /$ cork composites. Flexural and compressive strengths and moduli of the nanofilled composites are higher than those of the control sample, due to the uniform distribution of the nanoparticles into the PR that infiltrated into the cork pores, as shown in SEM and EDS analyses. Friction coefficient is enhanced by the $\mathrm{nSiC}$ presence, due to the abrasive properties of this compound. Thermal resistance is also improved with the addition of silicon carbide nanoparticles, both when the materials were subjected to temperature increase from 25 to $1000^{\circ} \mathrm{C}$ during TG-DSC analysis as well as when they were subjected to thermal shock directly at $1100^{\circ} \mathrm{C}$. The $\mathrm{nSiC}$ nanofiller with high thermal resistance was able to act as a protection agent for the $\mathrm{PR} /$ cork composites, resulting into less damaged samples after thermal shock, aiding the material to maintain its integrity and suffer lower mass loss. TG-DSC results are in accordance with thermal shock test, as the $2 \% \mathrm{nSiC}$-based samples present a non-linear increase of the residual mass (function of $\mathrm{nSiC}$ content), suggesting that it corresponds to a composite residue. This indicates that $\mathrm{nSiC}$ is able to act as a thermal barrier agent, preventing the combustion propagation in the composite. The results obtained in this study sustain this type of nanocomposite material as potential candidate for thermal protection (i.e., ablative) application in aeronautic and aerospace industry.

\section{Acknowledgement}

This work has been funded by the Sectorial Operational Programme Human Resources Development 2007-2013 of the Ministry of European Funds through the Financial Agreement POSDRU/159/1.5/S/134398.

\section{References}

[1] Gregori M L, Barros E A, Filho G P, Pardini L C and Costa S F 2009 J. Aerospace Technol. Manag. 163

[2] Bouilly J-M, Dariol L and Leleu F 2006 In Proceedings of the 5th European Workshop on TPS and Hot Structures-ESTEC, Noordwijk, 17-19 May 2006

[3] National Aeronautics and Space Administration (NASA) 1967 Sykes F G (ed) NASA Technical Report no. D-3810

[4] Knop A and Pilato L A 1985 Phenolic resin: chemistry, application and performance (Berlin: Springer-Verlag)

[5] Kanno Y 1993 In Proceedings of the 9th international conference on composite materials, Madrid, Spain, p 120

[6] Laub B and Venkatapathy E 2003 In Proceedings of the international workshop on planetary probe atmospheric entry and descent trajectory analysis and science, Lisbon, Portugal, 6-9 October 2003 
[7] NATO Science \& Technology Organization 2007 Re-entry flight experiments lessons learned-the atmospheric reentry demonstrator ARD in: Flight experiments for hypersonic vehicle development $\mathrm{Ph}$ Tran, J C Paulat and P Boukhobza (eds) Educational notes no. RTO-EN-AVT-13 (online report)

[8] Chicarro A, Martin P and Trautner R 2004 The Mars express mission: an overview, in: A Wilson (ed), Mars express: an European mission to the Red Planet (ESA SP-1240) (Noordwijk, The Netherlands: ESA Publications Division)

[9] Bouilly J-M, Bonnefond F, Dariol L, Jullien P and Leleu F 2006 In Proceedings of the 4th International Planetary Probe Workshop, Pasadena, California, USA, 27-30 June 2006

[10] Pinaud G, Van Eekelen A J and Bouilly J-M 2014 AEROFAST: development of cork TPS material and a $3 \mathrm{~d}$ comparative thermal/ablation analysis of an apollo \& a biconic sled shape for an aerocapture mission, available online at: http://solarsystem. nasa.gov/docs/7_aerofast_paper.pdf

[11] Deuri A S, Bhowmick A K, Ghosh R, John B, Sriram T and De S K 1988 Polym. Degrad. Stabil. 2121

[12] Castro O, Silva J M, Devezas T, Silva A and Gil L 2010 Mater. Des. 31425

[13] Silva J M, Gamboa P V, Nunes C, Paulo L and Franco N 2011 In Proceedings of the 52nd AIAA/ASME/ASCE/AHS/ASC structures, structural dynamics and materials conference, Denver, Colorado, 4-7 April 2011

[14] Mir A, Bezzazi B, Zitoune R and Collombet F 2012 Mechanics 1820

[15] Gul J, Saleemi A, Mirza S, Feroze N and Mansha M 2010 Plast. Rubber Compos. 3928
[16] Raeisia H R H, Razzaghia M, Bahramiana A R and Kashani M R 2015 Procedia Mater. Sci. 11527

[17] Kucner L K and McManus H L 1994 In Proceedings of the 26th international SAMPE technical conference, vol 44, p 341-353, Paris, France, October 1994

[18] Sanoj P and Kandasubramanian B 2014 J. Compos. Article ID 825607, https://doi.org/10.1155/2014/825607

[19] Kang P H and Yang H S 1998 Korean. J. Chem. Eng. 15 580

[20] Liao C Z and Tjon S C 2010 e-Polymers 1

[21] Cao J P, Zhao J, Zhao X, Hu G H and Dang Z M 2013 J. Appl. Polym. Sci. 130638

[22] Arun P S, Sathish S and Narendhar C 2014 Int. J. Curr. Eng. Technol. 2247

[23] Pelin G, Pelin C-E, Stefan A, Dinca I, Ficai A, Andronescu E and Trusca R 2016 Bull. Mater. Sci. 39769

[24] International Organization for Standardization 2010 SR EN ISO 178 Standard-Plastic-Determination of flexural properties

[25] ASTM International 2009 ASTM D 1074-Standard test method for compressive strength of bituminous mixtures

[26] Su W-F 2013 Principles of polymer design and synthesis (Berlin: Springer-Verlag)

[27] ASTM International 2009 ASTM D 446-07-Standard Specifications and Operating Instructions for Glass Capillary Kinematic Viscometers

[28] Fan J and Kim-Ho Chu P 2014 Silicon carbide nanostructures: fabrication, structure, and properties (Springer), https://doi. org/10.1007/978-3-319-08726-9 Switzerland 